\title{
KinetOSTATIC ANALYSIS OF THE SERVICE MOBILE ROBOT WITH MANIPULATOR
}

\author{
Plotnikov Aleksey \& Pryanichnikov Valentin
}
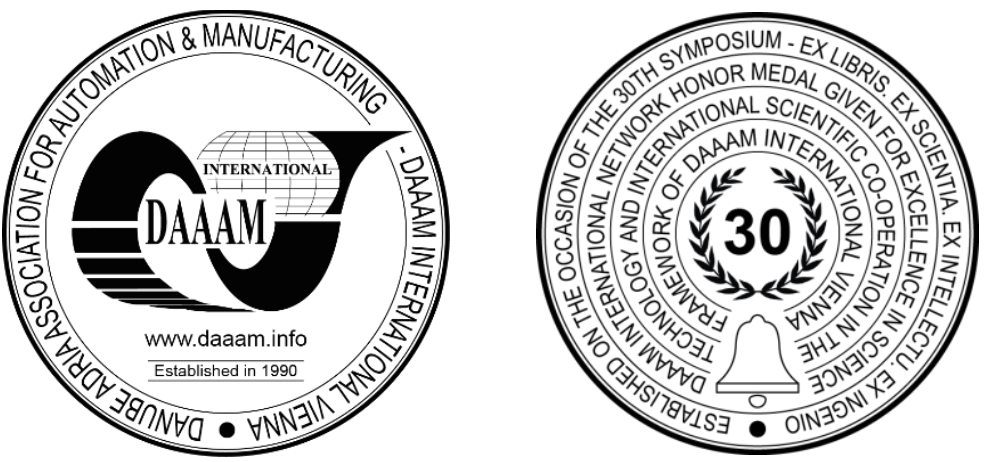

This Publication has to be referred as: Plotnikov, A[leksey] \& Pryanichnikov, V[alentin] (2021). Kinetostatic Analysis of the Service Mobile Robot with Manipulator, Proceedings of the 32nd DAAAM International Symposium, pp.04460453, B. Katalinic (Ed.), Published by DAAAM International, ISBN 978-3-902734-33-4, ISSN 1726-9679, Vienna, Austria

DOI: $10.2507 / 32$ nd.daaam.proceedings.065

\begin{abstract}
When creating service mobile robots with manipulators for operation in cramped rooms (home/office/hospitals), there is a problem of capturing and transporting both small-sized objects and those, that make up a significant part of the robot's weight. When constructing the control of the lifting process of such objects, the task of dynamic capture arises while maintaining the stability of the robot. The article considers the solution of the dynamics problem for the AMUR-307 mobile robot with a two-armed manipulator circuit. The basis for the construction of such control is proposed to take the solution of the dynamics problem using the kinetostatics method. The kinematics of the robot is such, that to simplify calculations, the robot body system can be considered as two-dimensional. In the process of analyzing the dynamics of the system, three main parts are distinguished: the upper links of the manipulator with the object of manipulation, the lower links of the manipulator with the drive elements of the upper links, the transport platform of the robot. The distribution of forces in different parts of a robot with a manipulator is considered. The dependence of the forces and moments of inertia on the motion of the system are found. The resulting equations linking the generalized coordinates of the robot with the efforts of the drives are a reliable basis for generating synergies for capturing, loading and moving heavy objects by the robot.
\end{abstract}

Keywords: Robotics; Mobile Service robot; Movement synergy algorithms for heavy object manipulation; Kinetostatic dynamics analysis.

\section{Introduction}

A dictionary of motion synergies is currently being developed to control the manipulator of the Amur-307 mobile robot. The synergies of movements are coordinating changes in articular angles (kinematic synergy), articular moments (dynamic synergy) [1], as well as propulsion drives. In the process of creating the system, a dictionary of robot actions is formed, which includes a set of standard robot movements with a manipulator, depending on the task being performed and the situation. These elementary sequences of actions are formed by showing the operator executed movements of the manipulator and the mobile platform of the robot using the inverse kinematics solution method [3] and dynamically justified movements [2], using virtual models of the robot and/or a real service robot. 
Let's take a closer look at one of the synergies - an algorithm for capturing an object by a robot, that has a mass comparable to the mass of the robot itself. This action is dangerous because in the process of its implementation, the robot may overturn due to a sharp forward shift of the center of mass of the robot + object system. The proposed object capture strategy is as follows (Fig. 1):

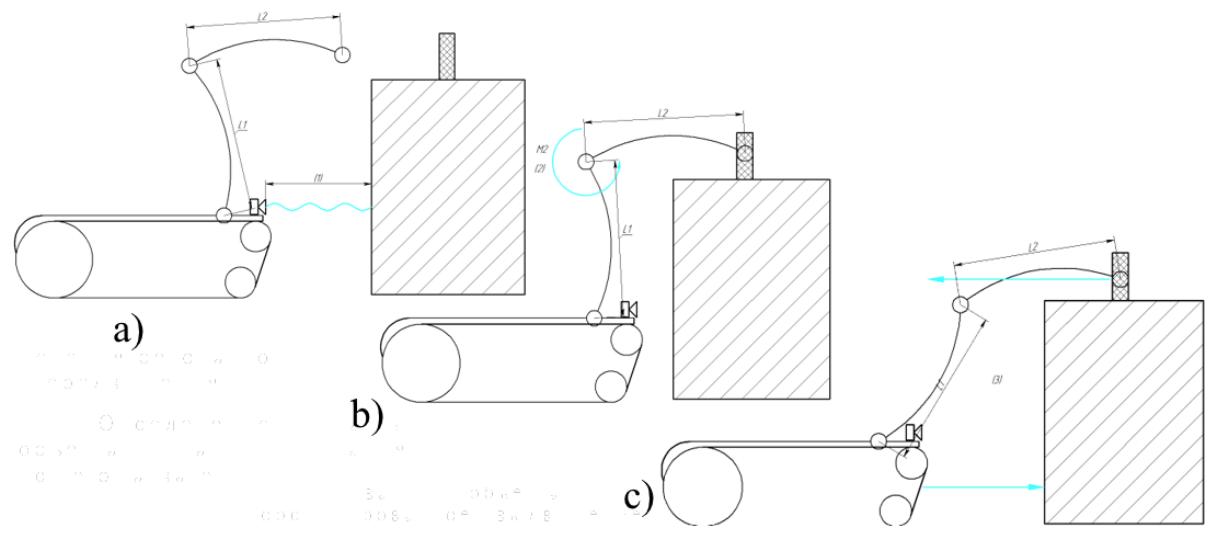

Fig. 1. The proposed object capture strategy

a) navigation system data is used to determine the safe area of movement during the capture;

b) the mass of the manipulating object is determined, when it is captured, using a special trial movement;

c) the object of manipulation is transferred inside the service area to the transport table, while the robot is moved forward in a coordinated manner to maintain balance.

To carry out the operations of estimating the mass of the object of manipulation and the implementation of a complex capture movement, it is necessary to solve the problem of system dynamics. In the literature, the solution of problems of robot dynamics by the kinetostatics method is widely described on the example of industrial robots [4], [5]. These techniques find their application in the work on the controling of manipulative robots [6]. For mobile robots, dynamics analysis is often performed using third-party systems for solving the dynamics problem [7] or using the Lagrange method [8], [9]. However, these techniques are poorly suited for solving dynamics problems on a mobile platform. The analytical solutions proposed in this work are obtained as a result of calculation by the kinetostatics method, which has a significant advantage in the speed of work and complexity of calculations. This is achieved by the absence of additional software (for example, Simulink) required for calculation by third-party software packages, and integration operations in the case of a Lagrange solution.

\section{System description}

The Amur 307 service robot consists of a tracked platform with a three-stage manipulator (Fig. 2).

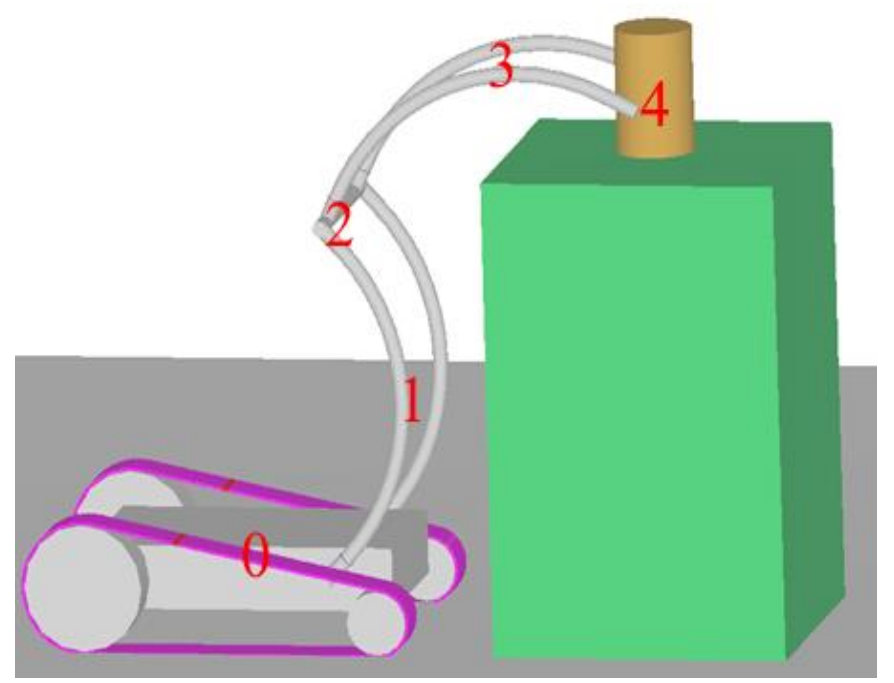

Fig. 2. Elements of the robot model 
Due to the symmetry of the robot's design, as well as the fact that the movement of lifting the load occurs without turning the robot, analysis of the dynamics of the described movement can be reduced to a two-dimensional problem. When conducting a kinetostatic [4] analysis of a robot with a load, the system should be divided into 3 parts: the transport platform (Fig.2, pos. 0), the lower links of the manipulator (Fig.2, pos. 1-2), the upper links of the manipulator (Fig.2, pos. 3-4).

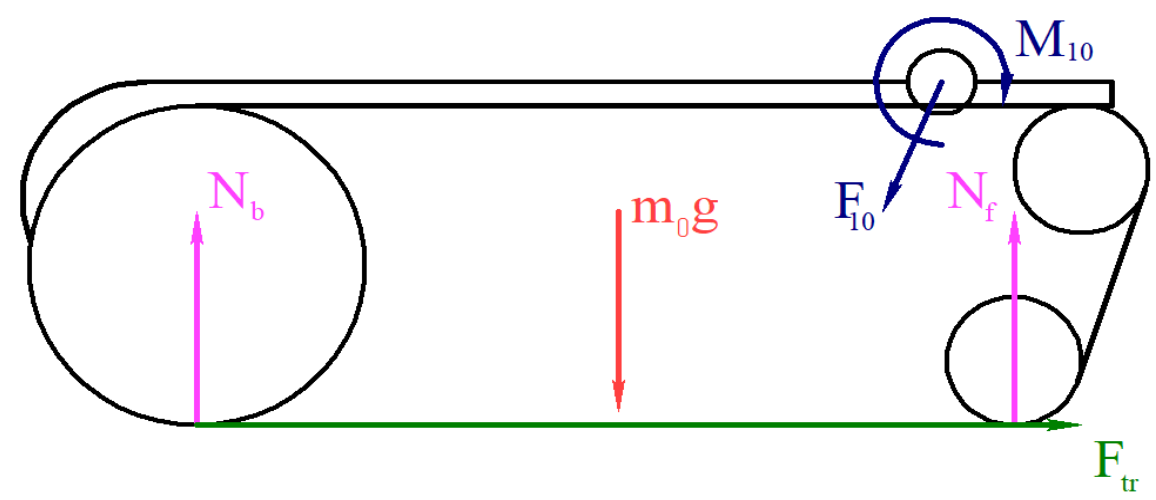

Fig. 3. Distribution of forces in the robot's transport platform

The following forces act on the transport platform (Fig.3.):

$\mathrm{m}_{0} \mathrm{~g}$ - gravity force of the transport platform;

$\mathrm{N}_{\mathrm{f}}, \mathrm{N}_{\mathrm{b}}$ - the reaction forces of the support acting on the front and rear rollers, respectively. In view of the symmetry of the problem and the transition to two- dimensional consideration are taken as the sum of the corresponding left and right reactions;

$\mathrm{F}_{\mathrm{tr}}$ - the traction force of the robot's tracked drive, equal to the sum of the traction forces of the left and right tracks; $\mathrm{F}_{10}, \mathrm{M}_{10}$ - force and moment of reaction of the connection from the lower links of the manipulator.

As shown (Fig. 2), the lower links of the robot manipulator (Fig. 2, pos. 1) connecting the transport platform with structural elements (Fig. 2, pos. 2). Structural elements (Fig. 2, pos. 2) provide a connection between the upper and lower links of the manipulator. Due to the compactness of the element (Fig. 2, pos. 2), it is considered without taking into account its dimensions together with the lower links of the manipulator. Based on the above, the following forces act on the lower link (Fig. 4.):

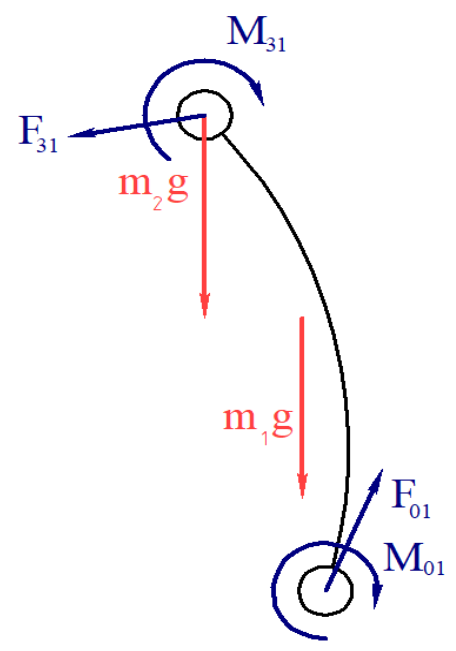

Fig. 4. The distribution of forces in the lower link of the robot manipulator.

$\mathrm{m}_{1} \mathrm{~g}$ - the gravity force of the lower link of the manipulator, due to the symmetry of the design and the transition to a twodimensional consideration of the problem, the mass of the structural element in question is assumed to be equal to the sum of the masses of the lower links of the manipulator;

$\mathrm{m}_{2} \mathrm{~g}$ - gravity of structural elements;

$\mathrm{F}_{01}$ - the gravity force of the structural elements;

$\mathrm{M}_{01}$ - is the moment of reaction from the transport platform, due to the drive force of the robot manipulator.

$\mathrm{F}_{31}, \mathrm{M}_{31}$ - force and moment of reaction of the connection from the upper links of the manipulator. 
The upper links of the robot manipulator (Fig. 2, pos. 3), is connected to the lower links by means of structural elements (Fig. 2, pos. 2). At the ends of the upper links, there is a gripping device with the object of manipulation. The object of manipulation and gripping devices are considered without taking into account their size together with the upper links of the manipulator. Based on the above, the following forces act on the upper link (Fig. 6.):

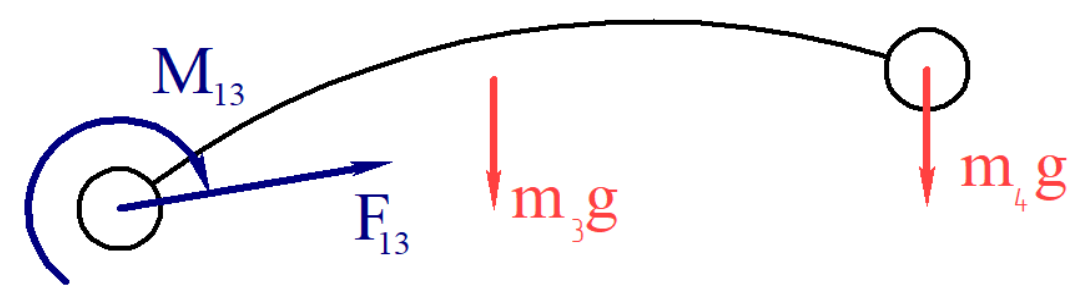

Fig. 5. Distribution of forces in the upper link of the robot manipulator

$\mathrm{m}_{3} \mathrm{~g}$-the gravity force of the upper link of the manipulator, due to the symmetry of the design and the transition to a twodimensional consideration of the problem, the mass of the considered structural element is assumed to be equal to the sum of the masses of the upper links of the manipulator;

$\mathrm{m}_{4} \mathrm{~g}$ - the total gravity force of the object of manipulation and gripping devices;

$\mathrm{F}_{13}$ - is the moment of reaction from the transport platform, due to the drive force of the robot manipulator;

$\mathrm{M}_{13}$ - the moment of reaction from the transport platform, due to the drive force of the robot manipulator.

It is necessary to find the relationship between the efforts of the manipulator drives $M_{13}(t), M_{01}(t)$, the efforts of the caterpillar drive $F_{t r}(t)$ from the generalized coordinates $\varphi_{1}(t), \varphi_{2}(t), s_{0}(t)$. Where $\varphi_{1}(t)$ is the rotational coordinate of the lower link of the manipulator, $\varphi_{2}(\mathrm{t})$ is the rotational coordinate of the upper link of the manipulator, $\mathrm{s}_{0}(\mathrm{t})$ is the translational movement of the transport platform during capture.

\section{Objects acceleration and forces of inertia}

To carry out kinetostatic analysis, in accordance with the Dalembert - Lagrange principle, the main vectors and moments of inertia forces applied at their centers of mass should be added to the forces acting on the manipulator links. To find the inertia forces, it is necessary to determine the acceleration of the masses of the system. The coordinate systems used in the calculations are shown in (Fig.7).

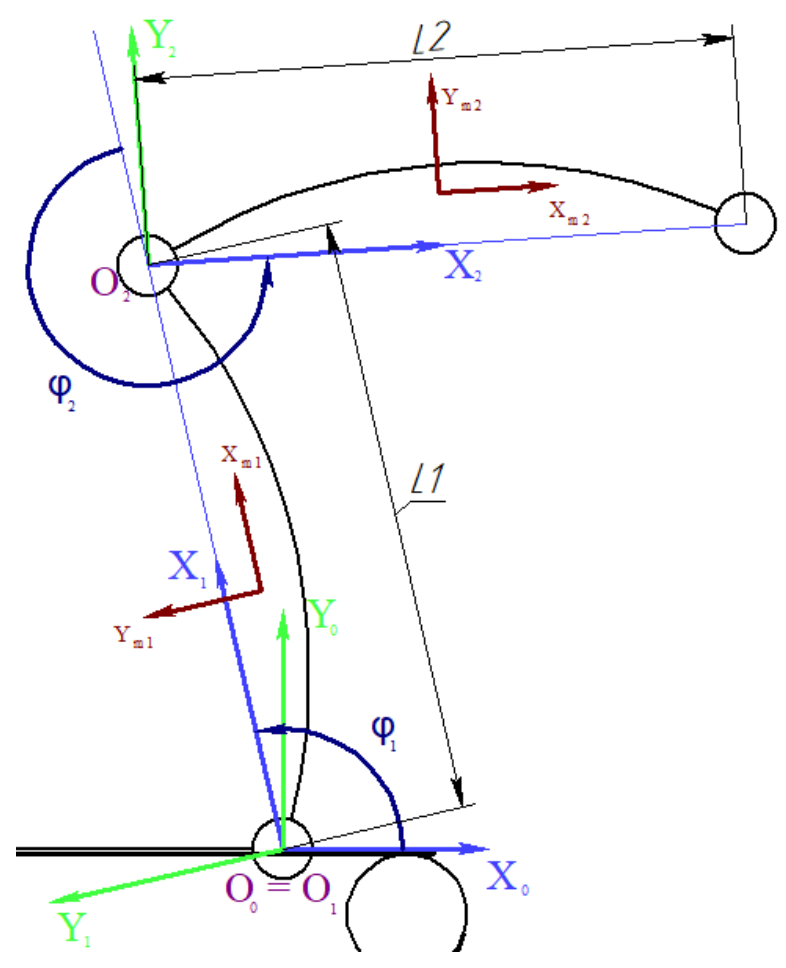

Fig. 6. Coordinate systems of the robot manipulator. 
Acceleration of the robot's transport platform during linear movement $\mathrm{s}_{0}(\mathrm{t})$ “(1)".

$$
\vec{a}_{m 0}=\left(\begin{array}{c}
\frac{d^{2} s_{0}}{d t^{2}} \\
0 \\
0
\end{array}\right)
$$

Equation of accelerations of the lower links of the manipulator "(2)".

$$
\overrightarrow{a_{m 1}}=\overrightarrow{a_{m 1}^{\varphi_{1}}}+\overrightarrow{a_{m 1}^{s_{0}}}=\overrightarrow{a_{m 1}^{n}}+\overrightarrow{a_{m 1}^{t}}+\overrightarrow{a_{m 1}^{s_{0}}}
$$

The position of the center of mass of the lower links of the manipulator is represented as the vector $\overrightarrow{R_{m 1}}$ in the coordinate system of the lower links $\mathrm{X}_{1} \mathrm{Y}_{1}$. Taking into account the position of the center of mass of the links with the angle of location "(3)", the acceleration equations in the coordinate system associated with the lower link of the robot arm will take form "(4)".

$$
\begin{aligned}
\tau_{m 1} & =\tan ^{-1} R_{m 1 Y} / R_{m 1 X} \\
\vec{a}_{m 1} & =\left(\begin{array}{ccc}
\cos \tau_{m 1} & -\sin \tau_{m 1} & 0 \\
\sin \tau_{m 1} & \cos \tau_{m 1} & 0 \\
0 & 0 & 1
\end{array}\right)\left(\begin{array}{c}
-\left(\frac{d \varphi_{1}}{d t}\right)^{2} \overrightarrow{\left|R_{m 1}\right|} \\
\frac{d^{2} \varphi_{1}}{d t^{2}} \overrightarrow{\left|R_{m 1}\right|} \\
0
\end{array}\right)+\left(\begin{array}{ccc}
\cos \varphi_{1} & \sin \varphi_{1} & 0 \\
-\sin \varphi_{1} & \cos \varphi_{1} & 0 \\
0 & 0 & 1
\end{array}\right) \vec{a}_{m 0}
\end{aligned}
$$

Acceleration equation for structural elements of the manipulator link “(5)".

$$
\vec{a}_{m 2}=\overrightarrow{a_{m 2}^{\varphi_{1}}}+\overrightarrow{a_{m 2}^{s_{0}}}=\overrightarrow{a_{m 2}^{n}}+\overrightarrow{a_{m 2}^{t}}+\overrightarrow{a_{m 0}^{s_{0}}}
$$

In the coordinate system associated with the lower link of the manipulator "(5)" takes the form "(6)".

$$
\vec{a}_{m 2}=\left(\begin{array}{c}
-\left(\frac{d \varphi_{1}}{d t}\right)^{2} L_{1} \\
\frac{d^{2} \varphi_{1}}{d t^{2}} L_{1} \\
0
\end{array}\right)+\left(\begin{array}{ccc}
\cos \varphi_{1} & \sin \varphi_{1} & 0 \\
-\sin \varphi_{1} & \cos \varphi_{1} & 0 \\
0 & 0 & 1
\end{array}\right) \vec{a}_{m 0}
$$

Equation for accelerations of the upper links of the manipulator "(7)".

$$
\overrightarrow{a_{m 3}}=\overrightarrow{a_{m 3}^{\varphi_{2}}}+\overrightarrow{a_{m 2}^{\varphi_{1}}}+\overrightarrow{a_{m 0}^{s_{0}}}
$$

Taking into account the kinematic scheme of the manipulator, the equation " (7)" takes the form "(8)":

$$
\begin{aligned}
& \overrightarrow{a_{m 3}}=\left(\begin{array}{ccc}
\cos \tau_{m 3} & -\sin \tau_{m 3} & 0 \\
\sin \tau_{m 3} & \cos \tau_{m 3} & 0 \\
0 & 0 & 1
\end{array}\right)\left(\begin{array}{c}
-\left(\frac{d\left(\varphi_{1}+\varphi_{2}\right)}{d t}\right)^{2} \overrightarrow{\left|R_{m 3}\right|} \\
\frac{d^{2}\left(\varphi_{1}+\varphi_{2}\right)}{d t^{2}} \overrightarrow{\left|R_{m 3}\right|} \\
0
\end{array}\right)+ \\
& +\left(\begin{array}{ccc}
\cos \varphi_{2} & \sin \varphi_{2} & 0 \\
-\sin \varphi_{2} & \cos \varphi_{2} & 0 \\
0 & 0 & 1
\end{array}\right)\left(\begin{array}{c}
-\left(\frac{d \varphi_{1}}{d t}\right)^{2} L_{1} \\
\frac{d^{2} \varphi_{1}}{d t^{2}} L_{1} \\
0
\end{array}\right)+\left(\begin{array}{ccc}
\cos \left(\varphi_{1}+\varphi_{2}\right) & \sin \left(\varphi_{1}+\varphi_{2}\right) & 0 \\
-\sin \left(\varphi_{1}+\varphi_{2}\right) & \cos \left(\varphi_{1}+\varphi_{2}\right) & 0 \\
0 & 0 & 1
\end{array}\right) \vec{a}_{m 0}
\end{aligned}
$$

Equation of accelerations of the manipulated object "(9)", “(10)".

$$
\overrightarrow{a_{m 4}}=\overrightarrow{a_{m 4}^{\varphi 2}}+\overrightarrow{a_{m 4}^{\varphi 1}}+\overrightarrow{a_{m 4}^{s 0}}
$$




$$
\begin{aligned}
& \overrightarrow{a_{m 4}}=\left(\begin{array}{c}
-\left(\frac{d \varphi_{1}}{d t}+\frac{d \varphi_{2}}{d t}\right)^{2} L_{2} \\
\left(\frac{d^{2} \varphi_{1}}{d t^{2}}+\frac{d^{2} \varphi_{2}}{d t^{2}}\right)^{2} L_{2}
\end{array}\right)+\left(\begin{array}{ccc}
\cos \varphi_{2} & \sin \varphi_{2} & 0 \\
-\sin \varphi_{2} & \cos \varphi_{2} & 0 \\
0 & 0 & 1
\end{array}\right)\left(\begin{array}{c}
-\left(\frac{d \varphi_{1}}{d t}\right)^{2} L_{1} \\
\frac{d^{2} \varphi_{1}}{d t^{2}} L_{1} \\
0
\end{array}\right)+ \\
& +\left(\begin{array}{ccc}
\cos \left(\varphi_{1}+\varphi_{2}\right) & \sin \left(\varphi_{1}+\varphi_{2}\right) & 0 \\
-\sin \left(\varphi_{1}+\varphi_{2}\right) & \cos \left(\varphi_{1}+\varphi_{2}\right) & 0 \\
0 & 0 & 1
\end{array}\right) \vec{a}_{m 0}
\end{aligned}
$$

The main moments of the inertia forces of the upper "(12)" and the lower links of the manipulator "(11)" relative to their centers of mass.

$$
\begin{aligned}
& \vec{M}_{1}^{I}=-\left(\begin{array}{c}
0 \\
0 \\
J_{1 z}
\end{array}\right) \frac{d^{2} \varphi_{1}}{d t^{2}} \\
& \vec{M}_{3}^{I}=-\left(\begin{array}{c}
0 \\
0 \\
J_{3 z}
\end{array}\right)\left(\frac{d^{2} \varphi_{1}}{d t^{2}}+\frac{d^{2} \varphi_{2}}{d t^{2}}\right)
\end{aligned}
$$

The main vectors of inertia forces of the transport platform "(13)", lower "(14)" and upper "(16)" links, structural elements of the robot manipulator "(14)", object of manipulation "(17)":

$$
\begin{aligned}
& \overrightarrow{F_{0}^{I}}=-m_{0}\left(\begin{array}{c}
\frac{d^{2} s_{0}}{d t^{2}} \\
0 \\
0
\end{array}\right) \\
& \overrightarrow{F_{1}^{I}}=-m_{1} \overrightarrow{a_{1}} \\
& \overrightarrow{F_{2}^{I}}=-m_{2} \overrightarrow{a_{2}} \\
& \overrightarrow{F_{3}^{I}}=-m_{3} \overrightarrow{a_{3}} \\
& \overrightarrow{F_{4}^{I}}=-m_{4} \overrightarrow{a_{4}}
\end{aligned}
$$

\section{Forces and moments equations}

To find the values of reaction forces, in accordance with the principle of kinetostatics, the equations of forces and moments acting on each body of the system are written.

For the upper links of the manipulator, the "(18)", "(19)", "(20)" are valid.

$$
\begin{aligned}
& \vec{F}_{13}+m_{3} \vec{g}+m_{4} \vec{g}-m_{3} \vec{a}_{m 3}-m_{4} \vec{a}_{m 4}=0 \\
& \vec{F}_{13}=m_{3} \vec{a}_{m 3}+m_{4} \vec{a}_{m 4}-m_{3} \vec{g}-m_{4} \vec{g} \\
& \vec{M}_{13}=-1\left(\overrightarrow{R_{m 3}} \times m_{3} \vec{g}+L_{2} \overrightarrow{X_{2}} \times m_{4} \vec{g}-\overrightarrow{R_{m 3}} \times m_{3} \vec{a}_{m 3}-L_{2} \overrightarrow{X_{2}} \times m_{4} \vec{a}_{m 4}-\right. \\
& \left.-\left(\begin{array}{c}
0 \\
0 \\
J_{3 z}+m_{3}\left|\overrightarrow{R_{m 3}}\right|^{2}
\end{array}\right)\left(\frac{d^{2} \varphi_{1}}{d t^{2}}+\frac{d^{2} \varphi_{2}}{d t^{2}}\right)\right)
\end{aligned}
$$

For the lower links of the manipulator, the "(21)”, “(22)”, “(23)”, “(24)”, “(25)” are valid.

$$
\begin{aligned}
& \vec{F}_{31}=-\vec{F}_{13} \\
& \vec{M}_{31}=-\vec{M}_{13}
\end{aligned}
$$




$$
\begin{aligned}
& \vec{F}_{01}+\vec{F}_{31}+m_{1} \vec{g}+m_{2} \vec{g}-m_{1} \vec{a}_{m 1}-m_{2} \vec{a}_{m 2}=0 \\
& \vec{F}_{01}=m_{1} \vec{a}_{m 1}+m_{2} \vec{a}_{m 2}-m_{1} \vec{g}-m_{2} \vec{g}+\vec{F}_{13} \\
& \vec{M}_{01}=-1\left(\overrightarrow{R_{m 1}} \times m_{1} \vec{g}+L_{1} \overrightarrow{X_{1}} \times m_{2} \vec{g}-\overrightarrow{R_{m 1}} \times m_{1} \vec{a}_{m 1}-L_{1} \overrightarrow{X_{1}} \times m_{2} \vec{a}_{m 2}-\right. \\
& \left.-\left(\begin{array}{c}
0 \\
0 \\
J_{1 z}+m_{1}\left|\overrightarrow{R_{m 1}}\right|^{2}
\end{array}\right) \frac{d^{2} \varphi_{1}}{d t^{2}}+\vec{M}_{31}\right)
\end{aligned}
$$

Equations of moments of forces and forces of inertia, relative to its center of mass, are compiled for the transport platform.

$$
\begin{aligned}
& \vec{M}_{10}=-\vec{M}_{01} \\
& \vec{F}_{10}=-\vec{F}_{01} \\
& \vec{M}_{10}+\vec{h}_{m 0} \times \vec{F}_{t r}+\vec{r}_{F m 0} \times \vec{F}_{10}+\vec{r}_{N b m 0} \times \vec{N}_{b}+\vec{r}_{N f m 0} \times \vec{N}_{f}=0 \\
& \vec{h}_{m 0} \times \vec{F}_{t r}=-1\left(\vec{M}_{10}+\vec{r}_{F m 0} \times \vec{F}_{10}+\vec{r}_{N b m 0} \times \vec{N}_{b}+\vec{r}_{N f m 0} \times \vec{N}_{f}\right)
\end{aligned}
$$

The reaction forces of the supports are found from the equations of moments relative to the front "(31)" and rear "(30)" support points:

$$
\begin{aligned}
& \vec{r}_{N f N b} \times \vec{N}_{f}=-1\left(\vec{M}_{10}+\vec{r}_{F N b} \times \vec{F}_{10}+\vec{r}_{m N b} \times\left(m_{0} \vec{g}\right)-\vec{r}_{m 0 N b} \times m_{0} \vec{a}_{m 0}\right) \\
& \vec{r}_{N b N f} \times \vec{N}_{b}=-1\left(\vec{M}_{10}+\vec{r}_{F N f} \times \vec{F}_{10}+\vec{r}_{m N f} \times\left(m_{0} \vec{g}\right)-\vec{r}_{m 0 N f} \times m_{0} \vec{a}_{m 0}\right)
\end{aligned}
$$

\section{Conclusion}

As a result of solving a system of equations "(20)", "(26)", "(30)" the dependencies connecting the generalized coordinates of the robot $\mathrm{s}_{0}(\mathrm{t}), \varphi_{1}(\mathrm{t}), \varphi_{2}(\mathrm{t})$ with the moment of forces of the manipulator drives $\mathrm{M}_{1}(\mathrm{t}), \mathrm{M}_{2}(\mathrm{t})$, and the force of the tracks $F_{t r}(t)$ are found. Based on the obtained dependencies, it is possible to create algorithms for controlling the movements of the robot manipulator in the form of synergies. Equations "(18)", "(19)", "(20)" can also be used to determine the mass of the $\mathrm{m}_{4}$ manipulation object. The solution of the problem of determining the mass of the manipulating object can be carried out both by direct measurements using force-moment sensors, and analytically using current feedbacks and drive positions.

In the AMUR-307 service robot, it is more expedient to use an analytical method for determining the mass of the manipulated object, based on a sequential increase in the lifting force of the object by the manipulator and comparing this with the measurement of the coordinates of the robot manipulator. The capture of a relatively heavy object is accompanied by the simultaneous movement of the robot with acceleration towards the captured object. Such a complex movement, which includes the simultaneous movement of the manipulator and the robot mover, allows you to create a moment of inertia forces that ensure the equilibrium of the system. Based on the values of reaction forces in the supports from "(31)", "(32)" and by solving "(30)" it is possible to determine the direction and desired acceleration of the balancing movement of the robot.

The work demonstrates the possibility of using kinetostatics to implement finite analytical formulas, that allow us to build synergies for manipulator control with minimal computational/time costs.

\section{References}

[1] Methods of biomechatronics of the human hand simulator / A.K. Platonov, A.A. Frolov, E.V. Biryukova, V.E. Pryanichnikov, S.N. Yemelyanov // Preprints of M.V.Keldysh IPM RAS 2012. No. 82.40 p. URL: http://library.keldysh.ru/preprint.asp?id=2012-82

Методы биомехатроники тренажёра руки человека / А.К. Платонов, А.А. Фролов, Е.В. Бирюкова, В.Е. Пряничников, С.Н. Емельянов // Препринты ИПМ им. М.В.Келдыша РАН 2012. № 82 . 40 c. URL: http://library.keldysh.ru/preprint.asp?id=2012-82

[2] Biologically adequate principles of human hand exoskeleton control / A.A. Frolov, E.V. Biryukova, P.D. Bobrov, A.K. Platonov, V.E. Pryanichnikov. // Information-measuring and control systems (vol. Intelligent adaptive Robots, vol.8, No. 1-2), Moscow: Radio Engineering, 2013, vol.11, No. 4. -pp.7-18, ISSN 2070-0814

[3] Биологически адекватные принципы управления экзоскелетом руки человека / А.А. Фролов, Е.В. Бирюова, П.Д. Бобров, А.К. Платонов, В.Е. Пряничников. // Информационно-измерительные и управляющие системы 
(вып. Интеллектуальные адаптивные роботы, т.8, № 1-2), М.: Радиотехника, 2013, т.11, № 4. -C.7-18, ISSN 2070-0814

[4] Andreas Aristidou, Joan Lasenby, FABRIK: A fast, iterative solver for the Inverse Kinematics problem, Graphical Models, Volume 73, Issue 5, 2011, Pages 243-260, ISSN 1524-0703, https://doi.org/10.1016/j.gmod.2011.05.003.

[5] Mechanics of industrial robots: a textbook for higher education institutions: in 3 books. / Edited by K.V. Frolov and. I.Vorobyova. Book 1: Kinematics and dynamics / E.I. Vorobyov, S.A. Popov, G.I.Sheveleva. - M.: Higher School, 1988. - 304 p.

[6] Механика промышленных роботов: учебное пособие для втузов: в 3 кн. / Под ред. К.В. Фролова и. И. Воробьева. Кн. 1: Кинематика и динамика / Е.И. Воробьев, С.А. Попов, Г. И. Шевелева. - М.: Высш. шк., 1988. - 304 c.

[7] Kolovsky, M.Z. Fundamentals of the dynamics of industrial robots / M.Z. Kolovsky, A.V. Sloushch- - M.: Nauka. Gl. ed. phys. - mat. lit., 1988. - 240 p.

[8] Коловский, М.З. Основы динамики промышленных роботов / М.3. Коловский, А.В. Слоущ. - М.: Наука. Гл. ред. физ. - мат. лит., 1988. - 240 с.

[9] Anciporovich, P. P. Kinetostatic force analysis of a manipulator with 4 degrees of freedom / P. P. Anciporovich, V. K. Akulich, E. M. Dubovskaya // Theoretical and applied mechanics. Issue 28: International Scientific and Technical collection / edited by A.V. Chigarev; BNTU. - Minsk, 2013. - pp. 224-227

[10] Анципорович, П. П. Кинетостатический силовой анализ манипулятора с 4 степенями свободы / П. П. Анципорович, В. К. Акулич, Е. М. Дубовская // Теоретическая и прикладная механика. Выпуск 28: международный научно-технический сборник / под ред. А. В. Чигарева; БНТУ. - Минск, 2013. - С. 224-227

[11] Damic, V[jekoslav]; Cohodar, M[aida] \& Muratovic, M[unir] (2017). Dynamic Modelling of Mobile Robots Based on its 3D CAD Model, Proceedings of the 28th DAAAM International Symposium, pp.0144-0149, B. Katalinic (Ed.), Published by DAAAM International, ISBN 978-3-902734-11-2, ISSN 1726-9679, Vienna, AustriaDOI: 10.2507/28th.daaam.proceedings.019

[12] Du, Y. (2016). Kinematics and Dynamic Modeling and Simulation Analysis of Three-wheeled Mobile Robot, International Conference on Mechanics Design, Manufacturing and Automation (MDM 2016) ISBN: 978-1-60595-3540

[13] A. A. Hatab and R. Dhaouadi, "Dynamic modelling of differential-drive mobile robots using Lagrange and NewtonEuler methodologies: A unified framework," Adv. Robot. Autom., vol. 02, no. 02, 2013. 